\title{
Towards a Definition of the Sumerian Sergida
}

This talk will examine the group of Sumerian hymns known as „Sergidas“, identified as such by subscripts appended to the texts by Old Babylonian scribes. Its primary aim will be to explore the nature of the Sergidas as a corpus, which, on the surface, comprises a quite disparate group of compositions, with the ultimate goal of moving towards understanding the function of the Sergida hymn in Old Babylonian society.

In the first part of the talk, I will argue for the merits of approaching the Sergida hymns as a corpus and will discuss the potential value in more closely examining them and other hymnic groups defined by subscripts. In the second part, I will present an overview of the Sergida corpus and will briefly describe the content of the eleven known compositions belonging to it. Thirdly, I will address the disparity of the texts and discuss the difficulties one faces in attempting to identifiy common threads among them. Finally, I will discuss points of similarity among the Sergida hymns and will suggest possible ways in which they might have been understood in antiquity in to represent a single hymnic type. 